\title{
La difusión cultural y formación de públicos a través del póster
}

\author{
Luis Ruano, Alexander Astudillo \\ \& Marcelo Mamián
}

\begin{abstract}
Resumen
La comunicación digital hace que el póster, elemento comunicativo clásico, vuelva a ser masivo. A partir de esto, diferentes organizaciones culturales quieren cautivar y educar públicos en escenarios no escolarizados. Este trabajo tiene en cuenta una técnica de análisis visual, que contempla el acto de interpretación, el bagaje para la interpretación y el principio correlativo de la interpretación. El corpus documental está compuesto por pósteres de organizaciones culturales de la ciudad de Popayán, Colombia. Se concluye que través de los pósteres se puede evidenciar la existencia de una agenda cultural diversificada en la ciudad. Esta agenda manifiesta posiciones discursivas e imaginarios culturales múltiples.
\end{abstract}

Palabras clave:

póster; difusión cultural; formación de públicos; organizaciones culturales. 


\title{
The cultural diffusion and formation of publics through the poster
}

\begin{abstract}
Digital communication makes the poster, a classic communicative element, again massive. In this way, different cultural organizations want to captivate and educate the public in non-school settings. This work takes into account a technique of visual analysis, which contemplates the act of interpretation, the baggage of interpretation and the correlative principle of interpretation. The documentary corpus is composed of posters of cultural organizations of the city of Popayán, Colombia. It can be concluded that through the posters the existence of a diversified cultural agenda in the city can be evidenced. This agenda manifests multiple imaginary and discursive cultural positions.
\end{abstract}

Keywords: poster; cultural diffusion; training of publics; cultural organizations

\section{A difusão cultural e a formação de públicos através do cartaz}

Resumo: A comunicação digital torna o cartaz, um elemento comunicativo clássico, novamente maciço. Deste modo, diferentes organizações culturais querem cativar e educar o público em cenários não escolarizados. Este trabalho leva em consideração uma técnica de análise visual, que contempla o ato de interpretação, a bagagem de interpretação e o princípio correlativo de interpretação. O corpus documental é composto por cartazes de organizações culturais da cidade de Popayán, Colômbia. Conclui-se que através dos cartazes pode-se evidenciar a existência de uma agenda cultural diversificada na cidade. Esta agenda manifesta múltiplas posições imaginárias e discursivas culturais.

Palavras-chave: poster; difusão cultural; treinamento de públicos; organizações culturais

\section{La diffusion culturelle et la formation des publics à travers l'affiche}

Résumé: La communication numérique fait de l'affiche, un élément communicatif classique, à nouveau massif. De cette manière, différentes organisations culturelles veulent captiver et éduquer le public dans des environnements non scolaires. Ce travail prend en compte une technique d'analyse visuelle, qui contemple l'acte d'interprétation, le bagage de l'interprétation et le principe corrélatif de l'interprétation. Le corpus documentaire est composé d'affiches d'organisations culturelles de la ville de Popayán, en Colombie. On peut conclure qu'à travers les affiches, l'existence d'un agenda culturel diversifié dans la ville peut être mise en évidence. Cet agenda manifeste de multiples positions culturelles imaginaires et discursives.

Mots-clés: poster; diffusion culturelle formation de publics; organismes culturels 


\section{Introducción}

La reflexión sobre la relación ciudad-cultura no es nueva. De hecho, buena parte de la configuración social de las ciudades responde a una serie de dinámicas culturales que van generando las formas de ser y hacer lo urbano. Lo que subyace aquí es la manera como las sociedades se organizan en función de determinados espacios y lo que ocurre en ellos. Por tanto, es necesario ver la relación que se teje en torno a los espacios construidos (Lamy, 2006) como también las maneras como estos espacios se constituyen en escenarios de prácticas culturales que dinamizan el ser y quehacer urbanos (Pereira, 2007; Hurtado, 2011; Buendía, 2014). En este contexto, resulta clave ver cómo las dinámicas urbanas apelan a nuevos medios, discursos en y sobre lo urbano (Buendía, 2008), y procesos comunicativos para dotar de sentido aquello que las vivifica.

Con la aparición y emergencia de la comunicación digital, aparecen también nuevas formas, estéticas y posibilidades comunicativas. Bien señala Arango-Forero (2013) que la comunicación digital implica nuevas narrativas, nuevos medios, nuevos usos y apropiaciones y también, desde luego, nuevas audiencias.

Según Scolari (2008), el modelo de comunicación digital es más que emergente y podría considerarse ya como un nuevo paradigma; se basa en su carácter digital, la hipertextualidad, la reticularidad, la interactividad y la multimedialidad. En este orden de ideas, las prácticas y los productos culturales se enfrentan a un escenario de convergencia mediática que evidencia el carácter tecnosocial de la comunicación digital (Rosseti, 2007). Así, las formas de producir y, sobre todo, de informar y comunicar sobre los bienes culturales se están transformando, tal como también han cambiado las maneras de producir, circular y consumir información. Esto resulta importante en virtud de que la digitalización de contenidos (Hilbert \& Peres, 2009) permite una mayor circulación de dichos contenidos. Estos llegan ya no solo más personas, sino que llegan con mayor rapidez.

Ahora bien, ¿qué suponen estos cambios en términos del quehacer cultural y los bienes que producen y difunden? ¿Se trata solamente de un cambio de soportes o las herramientas digitales implican también un cambio en las estéticas y los imaginarios que proyectan? Estas preguntas resultan pertinentes cuando las planteamos en un contexto puntual como lo es la ciudad de Popayán (Colombia), pues ella expone el imaginario de ser una ciudad culta o cultural. Pero más allá del realce que tuvo durante la época de la colonia, en la actualidad, lo cultural de la ciudad parece diluido más en el pasado que una dinámica viva del presente.

\section{Ciudad y difusión cultural}

Popayán como ciudad contemporánea se ha estudiado muy poco. Hay muchos estudios e investigaciones sobre la ciudad pero su mirada se focaliza en lo que fue 
y representó Popayán en la Colonia y los primeros años de la República. Es decir, el análisis sobre la ciudad de las últimas décadas es muy escaso.

Los trabajos Whiteford (1963, 2008, y Crist, 2008), que se refieren básicamente a la ciudad de mediados del siglo XX, son un buen ejemplo de estudios urbanos contemporáneos sobre Popayán, pero más allá de estas referencias, no hay mayores datos. Más recientemente podemos encontrar a Tocancipá (2006) y García (2013), quienes se refieren al orden social de la ciudad y su estatuto colonial, respectivamente. En términos de narrativa urbana, es Buendía $(2014,2016)$ quien evidencia que Popayán posee una rica y sólida narrativa, que se ancla y fundamenta en el pasado remoto de la ciudad. Pero esta narrativa no es en sí misma del pasado sino, más bien, una construcción social que se consolidó, entre otras cosas, gracias al quehacer de la intelectualidad culta de Popayán del siglo pasado.

Por tanto, la idea según la cual Popayán es una ciudad culta, patricia (Romero, 1999) y letrada (Rama, 2004), corresponde básicamente a una narrativa que se ha construido en torno a la ciudad. Si bien esto no es necesariamente falso, sí es importante señalar que como relato construido bien puede tener elementos verdaderos, pero otros son exaltaciones de algunas características urbanas que se dieron en algún momento de la historia de la ciudad pero que, en el presente, sería difícil seguir sosteniendo (Buendía, 2017). Aun así, gracias a dicha narrativa urbana, Popayán posee una serie de patrones identitarios que le dan lustre y la proyectan de acuerdo con imaginarios urbanos específicos, asociados al pasado, la cultura y la religiosidad.

Pero, ¿qué pasa con la ciudad culta y letrada después de la aparición de los medios y soportes digitales? ¿Cuál es el tipo de ciudad que se difunde y proyecta hoy en día a través de estos medios y apelando a esta comunicación (la digital)? ¿Es Popayán todavía una ciudad culta? ¿Cómo se evidencia esto? ¿La agenda cultural de la ciudad es lo suficientemente rica y variada como para seguir sosteniendo que esta es una ciudad cultural?

Algunas hipótesis podrían plantearse frente a los estos interrogantes previamente formulados: 1) la ciudad sigue teniendo una narrativa hegemónica y esta simplemente está migrando hacia los soportes digitales; 2) la aparición de la comunicación digital de alguna manera "democratiza" las dinámicas comunicativas y en consecuencia permite la presencia de nuevos actores culturales que emergen con nuevos discursos urbanos; 3) la agenda cultural de la ciudad es más variada pero sigue existiendo una fuerte tensión entre prácticas culturales tradicionales hegemónicas y prácticas emergentes; 4) las dinámicas propias de la comunicación digital logran transformar los lenguajes de la cultura urbana y estamos ante un nuevo panorama que todavía está en proceso de construcción y falta mucho para su consolidación. Estas hipótesis bien pueden intentar explicar los nuevos fenómenos comunicativos que se dan en la ciudad, pero también pueden mostrar que tanto la ciudad como sus imaginarios se están transformando. 
En este contexto, vemos que, gracias a la comunicación digital, elementos comunicativos clásicos como el póster ganan nuevamente relevancia porque vuelven a resultar masivos, tanto en la circulación de su mensaje como en la cantidad de personas a las que se puede alcanzar gracias a las dinámicas que propicia la comunicación digital. No es que el póster sea un dispositivo digital sino más bien que, gracias a los dispositivos digitales (como herramientas comunicativas) el póster puede ser más visto y llegar más rápido a nuevos públicos (Ruano, Buendía \& Mamián, 2017). Aspectos estos que, años atrás, en tiempos de la comunicación analógica, no habrían sido posibles debido a la limitante física del póster, pues solo se llegaba a través de los que podían imprimirse y de aquellos que podían ver el póster fijo (o fijado) en un lugar específico (rígido e inamovible).

Este trabajo aborda el análisis de pósteres de cuatro organizaciones culturales ${ }^{1}$ que proponen una agenda cultural para la ciudad. Las propuestas de las organizaciones estudiadas son sólidas y reconocidas en Popayán, gozan de un gran nivel de aceptación y participación por parte de la ciudadanía y tienen activa presencia en medios digitales, bien sea a través de páginas web o en la red social Facebook.

\section{Aspectos metodológicos}

La investigación que aquí se expone se basa en una técnica de análisis visual (Pérez, 2014 y Panofsky, 1983), que examina las propuestas gráficas (pósteres) con las cuales algunas organizaciones de Popayán promueven la agenda cultural que le proponen a la ciudad. Dichas propuestas visuales se derivan de manera clara de unas posiciones discursivas (Gutiérrez del Álamo, 2010) sobre los imaginarios culturales de ciudad. Se entiende que cada forma de análisis conlleva una definición de discurso, por lo que siempre se regresa a la intención inicial, donde los objetivos marcan el tipo de análisis y técnicas. Hablamos de discurso (oral o visual), como una práctica social (Gutiérrez del Álamo, 2010).

El corpus documental se compone de fuentes visuales (3 pósteres promocionales y 1 portada de magazín), que se convierten en material de insumo para determinar el concepto pedagógico y el carácter educativo no escolarizado de la formación de públicos. Se parte del análisis de un código teórico medular con el software cualitativo Atlas.Ti 7, referente al concepto de "lo educativo", ligado a sus dimensiones "educación desescolarizada" y "formación de públicos".

Persiguiendo el código "nuevas alfabetizaciones", se rastreó información en la web (Facebook y páginas de organizaciones) desde la perspectiva de la etnografía virtual (Hine, 2004). Al tener la recopilación de la información visual, en el marco del análisis teórico, se asume para el tratamiento de los textos la propuesta metodológica de Erwin Panofsky (1983). En este contexto, se extrae la definición de tres códigos deductivos 
importantes para el desarrollo del análisis visual de las organizaciones culturales: preiconografía, iconografía e iconología.

La preiconografía es un punto de partida que el autor describe desde el concepto del reconocimiento, porque asume la lectura de la imagen desde el color, la forma y sus líneas, sin importar realmente lo que es. "Los objetos y acontecimientos cuya representación por medio de líneas, colores y volúmenes constituye el universo de los motivos, pueden ser identificados sobre la base de nuestra experiencia práctica" (Panofsky, 1983. 52).

Por su parte, la iconografía "se ocupa del asunto o significación de las obras de arte, en contraposición a su forma. [Se precisa] la diferencia entre asunto o significación, por un lado, y forma por el otro" (Panofsky, 1983. 45). En este orden de ideas, vale la pena aclarar que con el trabajo de los pósteres de las entidades culturales, se trata de indagar sobre la significación de las imágenes planteadas, las cuales dan forma a la manera como impactan y educan a la ciudadanía. Por esta razón, el presente trabajo de análisis parte del hecho de que "la iconografía constituye una descripción y clasificación de las imágenes [...] nos informa sobre cuándo y dónde determinados temas específicos recibieron una representación visible a través de unos u otros motivos específicos" (Panofsky, 1983: 52). En suma, la iconografía solo toma en cuenta una parte del conjunto de los elementos que intervienen en el contenido intrínseco de una obra de arte. Estos elementos deben ser explicitados para que la captación de este contenido llegue a fraguar en un todo articulado y comunicable (Panofsky, 1983).

Finalmente, la iconología "es un método de interpretación que procede más bien de una síntesis que de un análisis" (Panofsky, 1983: 51). Hace referencia, además, al descubrimiento y la interpretación de valores simbólicos, valores que dejan de estar establecidos en el autor de la imagen y pasan a ser manejados desde las individualidades de cada persona. Muchas veces los pósteres de los eventos llegan cargados de estilos, esquemas, colores, caligrafía y soporte, que permanecen en las personas, tienen un eco en el tiempo y se convierten en íconos.

Asumiendo estos tres conceptos que dentro de nuestro análisis operan como códigos, podemos establecer que la preiconografía gira en torno al reconocimiento; la iconografía constituye un carácter descriptivo y la iconología busca un reconocimiento y lugar en la historia. Se describe a continuación la ruta de análisis que se tuvo en cuenta a partir de los planteamientos que desarrolla Panofsky (1983), a partir de la siguiente matriz. 
Ruano, Astudillo \& Mamián: La difusión cultural y formación de públicos a través del póster

Tabla 1. Elementos de la interpretación

\begin{tabular}{|c|c|c|c|}
\hline $\begin{array}{l}\text { OBJETO DE INTER- } \\
\text { PRETACIÓN }\end{array}$ & $\begin{array}{l}\text { ACTO DE INTER- } \\
\text { PRETACIÓN }\end{array}$ & $\begin{array}{l}\text { BAGAJE PARA LA } \\
\text { INTERPRETACIÓN }\end{array}$ & $\begin{array}{l}\text { PRINCIPIO CORRECTIVO DE } \\
\text { LA INTERPRETACIÓN (HIS- } \\
\text { TORIA DE LA TRADICIÓN) }\end{array}$ \\
\hline $\begin{array}{l}\text { I. Asunto primario o } \\
\text { natural: a) fáctico, } \\
\text { y b) expresivo, que } \\
\text { constituyen el universo } \\
\text { de los motivos } \\
\text { artísticos }\end{array}$ & $\begin{array}{l}\text { Descripción } \\
\text { pre-iconográfica } \\
\text { (y análisis } \\
\text { pseudoformal) }\end{array}$ & $\begin{array}{c}\text { Experiencia práctica } \\
\text { (familiaridad con objetos } \\
\text { y acontecimientos }\end{array}$ & $\begin{array}{l}\text { Historia del estilo (estudio } \\
\text { sobre la manera en que, } \\
\text { en distintas condiciones } \\
\text { históricas, los objetos y } \\
\text { acontecimientos fueron } \\
\text { expresados mediante formas). }\end{array}$ \\
\hline $\begin{array}{l}\text { II. Asunto secundario } \\
\text { o convencional, que } \\
\text { constituyen el universo } \\
\text { de la imágenes, } \\
\text { historias y alegorías }\end{array}$ & Análisis iconográfico & $\begin{array}{l}\text { Conocimiento de } \\
\text { las fuentes literaria } \\
\text { (familiaridad con temas y } \\
\text { conceptos específicos) }\end{array}$ & $\begin{array}{l}\text { Historia de los tipos (estudio } \\
\text { sobre la manera en que, } \\
\text { en distintas condiciones } \\
\text { históricas, los temas o } \\
\text { conceptos específicos fueron } \\
\text { expresados mediante objetos y } \\
\text { acontecimientos). }\end{array}$ \\
\hline $\begin{array}{c}\text { III. Significación } \\
\text { intrínseca o contenido, } \\
\text { que constituye el } \\
\text { universo de los valores } \\
\text { simbólicos }\end{array}$ & $\begin{array}{l}\text { Interpretación } \\
\text { iconológica }\end{array}$ & $\begin{array}{c}\text { Intuición sintética } \\
\text { (familiaridad con las } \\
\text { tendencias esenciales } \\
\text { de la mente humana), } \\
\text { condicionada por } \\
\text { una psicología y } \\
\text { una "Weltanshauug" } \\
\text { (cosmovisión o visión del } \\
\text { mundo) }\end{array}$ & $\begin{array}{l}\text { Historia de los síntomas } \\
\text { culturales, o símbolos en } \\
\text { general (estudio sobre la } \\
\text { manera en que, en distintas } \\
\text { condiciones históricas, las } \\
\text { tendencias esenciales de } \\
\text { la mente humana fueron } \\
\text { expresadas mediante temas y } \\
\text { concepto específicos. }\end{array}$ \\
\hline
\end{tabular}

FUENTE: Erwin Panofsky. El significado en las artes visuales, 1983 (Adaptación de los autores).

Partiendo del objeto de interpretación (el póster), se establecen tres momentos de análisis: i) el asunto primario, ii) el asunto secundario y iii) el de significación intrínseca. Teniendo en cuenta estas brechas visuales, se comienza por dar cuenta de cada póster y por ende de cada organización, a partir de tres elementos: el acto de interpretación, el bagaje para la interpretación y el principio correlativo de la interpretación.

\section{Análisis visual e interpretativo de los póster de las organizaciones culturales}

Al tener la información visual de las organizaciones, se aplican los principios de análisis que plantea Erwin Panofsky (1983). Según Panofsky, son tres los momentos que se deben tener en cuenta para el desarrollo del análisis visual de las organizaciones culturales. Estos tres momentos son preiconografía, iconografía e iconología. De esta manera, se desarrolla el análisis por cada organización: 


\section{a)Popayán Cultural}

Es una propuesta cultural con un enfoque básicamente informativo. Tiene página web, Facebook e Instagram. Promociona la mayoría de eventos culturales y académicos que se realizan en la ciudad. Publica información de otros medios, temas locales o nacionales que traten el tema cultural o artístico. La organización ha ganado y consolidado un espacio como vitrina de difusión cultural de la ciudad. Su medio más conocido es un magazín que circula gratuitamente entre la ciudadanía y en él se presenta regularmente la agenda cultural que se oferta para la ciudad.

Figura 1. Portada magazín Popayán Cultural.

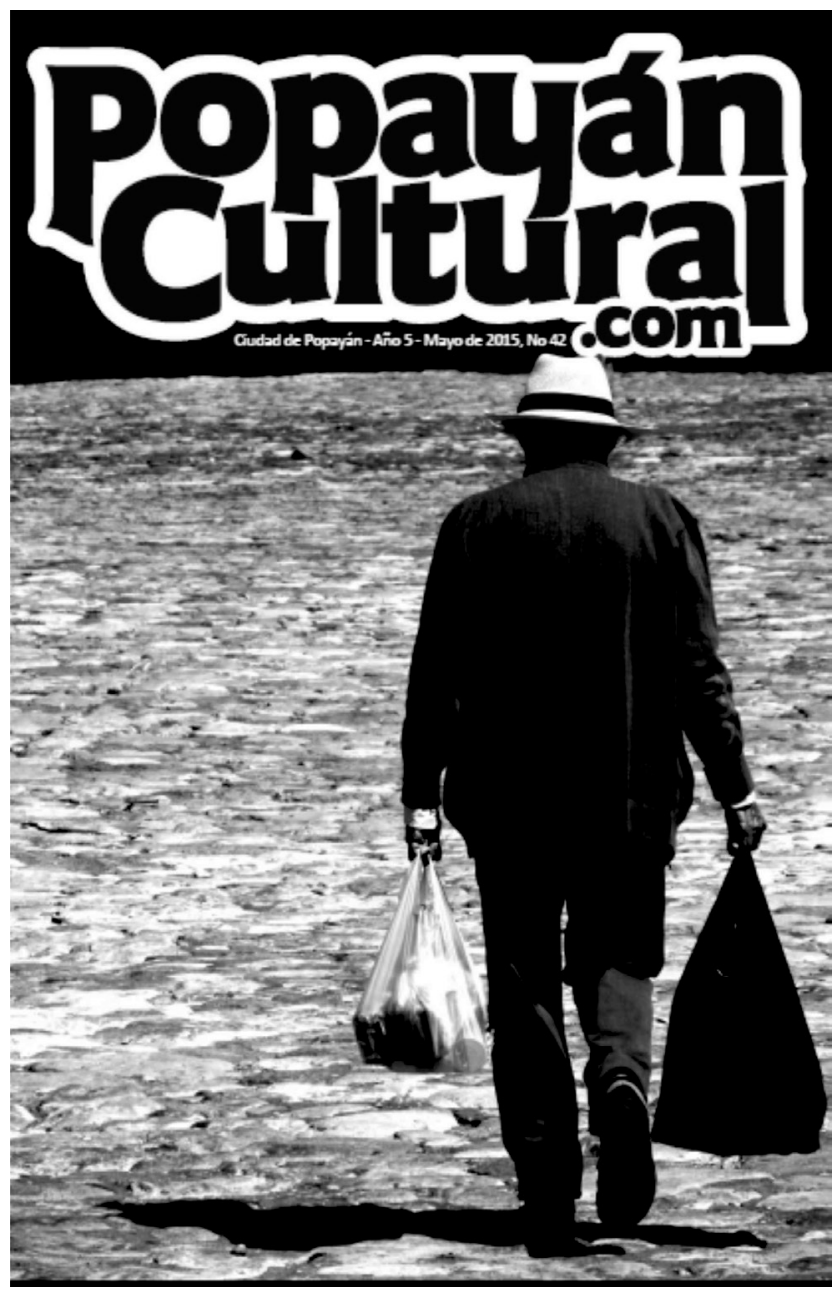

Fuente: Página web 
Tabla 2. Interpretación y análisis visual de Popayán Cultural

\begin{tabular}{|c|c|c|}
\hline $\begin{array}{c}\text { DESCRIPCIÓN } \\
\text { PREICONOGRÁFICA }\end{array}$ & $\begin{array}{c}\text { ANÁLISIS } \\
\text { ICONOGRÁFICO }\end{array}$ & $\begin{array}{l}\text { ANÁLISIS } \\
\text { ICONOLÓGICO }\end{array}$ \\
\hline $\begin{array}{l}\text { Portada de un magazín cultural } \\
\text { de la ciudad de Popayán, en } \\
\text { formato rectangular, puesto } \\
\text { de manera vertical y trabajada } \\
\text { en una monocromía donde } \\
\text { aparecen dos segmentos } \\
\text { importantes: en la parte superior } \\
\text { sobresalen unas letras y datos de } \\
\text { publicación y en la parte inferior } \\
\text { una imagen fotográfica que } \\
\text { pesa compositivamente al lado } \\
\text { derecho. Es una forma humana } \\
\text { que sugiere movimiento dada la } \\
\text { posición en la que se encuentra } \\
\text { la forma. La superficie sobre la } \\
\text { que reposa la figura humana deja } \\
\text { ver una textura en una tonalidad } \\
\text { gris que se extiende sobre toda la } \\
\text { zona rectangular del formato. }\end{array}$ & $\begin{array}{l}\text { La fotografía muestra un hombre } \\
\text { que camina sobre una calle } \\
\text { empedrada, llevando consigo } \\
\text { dos bolsas, una más grande } \\
\text { que la otra. La superficie de } \\
\text { piedra nos remite a la ciudad } \\
\text { colonial. El hombre da la espalda } \\
\text { al espectador. Se genera la } \\
\text { sensación de desequilibrio por las } \\
\text { bolsas que lleva en cada mano; } \\
\text { hace suponer que una es más } \\
\text { pesada que la otra. La sombra } \\
\text { que proyecta su cuerpo nos ubica } \\
\text { más o menos hacia el mediodía, } \\
\text { con un clima caluroso y soleado. } \\
\text { El personaje viste con tonos } \\
\text { oscuros, porque la mayor parte de } \\
\text { la figura está en negro, se destaca } \\
\text { el sombrero que lleva sobre su } \\
\text { cabeza y remite a una persona } \\
\text { mayor. Se podría decir que es } \\
\text { una imagen costumbrista, porque } \\
\text { muestra la cotidianidad de la } \\
\text { ciudad donde vive. Con respecto } \\
\text { a lo cronológico, el tiempo en } \\
\text { la fotografía parece haberse } \\
\text { suspendido. }\end{array}$ & $\begin{array}{l}\text { Es precisamente el objeto de } \\
\text { su creación lo que se debe } \\
\text { considerar, porque se trata de un } \\
\text { medio que posibilita la circulación, } \\
\text { difusión y publicidad de eventos, } \\
\text { así como de organizaciones } \\
\text { culturales. Su trabajo de } \\
\text { diseño, pensado para un grupo } \\
\text { social que consume eventos } \\
\text { culturales, independientemente } \\
\text { de estratificación social y de } \\
\text { formación académica, llega a } \\
\text { todos los individuos de manera } \\
\text { indistinta, abarcando diferentes } \\
\text { manifestaciones del arte y la } \\
\text { cultura. Su gratuidad posibilita } \\
\text { que sea un medio cultural masivo, } \\
\text { construyendo un imaginario } \\
\text { de "ciudad cultural" en los } \\
\text { habitantes de la ciudad. Su } \\
\text { circulación posibilita e incentiva } \\
\text { una formación de públicos, que } \\
\text { ven en la cultura un referente de } \\
\text { conocimiento. }\end{array}$ \\
\hline
\end{tabular}

El proyecto de Popayán Cultural, cobra una vitalidad inédita, porque emerge hacia todas las audiencias, mira a sus públicos desde una horizontalidad, todos reciben el mismo trato, se podría hablar de un modelo comunicativo mucho más "democrático" y hasta cierto punto, masivo.

\section{b) Festival de Música de Popayán - Fespo}

La corporación que se encarga de la celebración anual del Festival de Música Religiosa nació en 1964. Aunque el nombre del festival cambió temporalmente a Festival de Música de Popayán, este evento se realiza ininterrumpidamente durante la Semana Santa. El Festival publica en sus plataformas digitales (página web y Twitter), los nombres de los artistas invitados y los escenarios de su evento central. El Festival es uno de los eventos culturales más antiguos y de mayor continuidad en la ciudad. 
Figura 2. Póster Festival de Música Religiosa de Popayán.

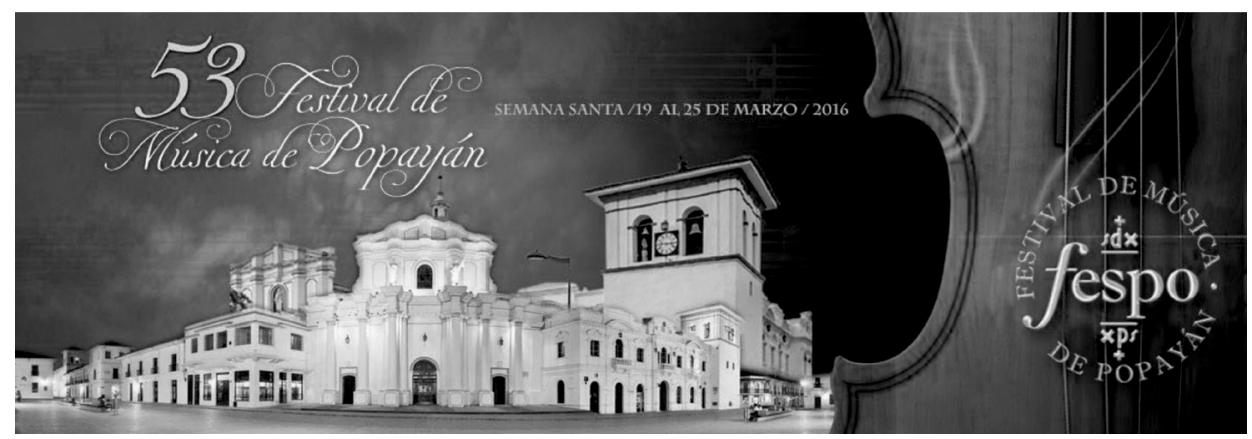

Fuente: Página Web

Tabla 3. Interpretación y análisis visual de Fespo

\begin{tabular}{|c|c|c|}
\hline Descripción preiconográfica & Análisis iconográfico & Análisis iconológico \\
\hline $\begin{array}{l}\text { El formato del póster es } \\
\text { rectangular y se ubica de manera } \\
\text { horizontal. Es un motivo diseñado } \\
\text { en varios colores, lo que supone } \\
\text { una impresión a varias tintas. El } \\
\text { colorido pasa del azul al marrón, } \\
\text { con una buena porción de blanco } \\
\text { en su esquema compositivo. El } \\
\text { diseño se divide en dos franjas } \\
\text { verticales muy bien definidas. } \\
\text { En la parte superior aparece } \\
\text { una caligrafía que da cuenta del } \\
\text { evento. La propuesta gráfica se } \\
\text { establece desde una composición } \\
\text { en donde se debe tener en } \\
\text { cuenta la disposición de los } \\
\text { elementos. Se nota una estructura } \\
\text { arquitectónica que ejerce peso en } \\
\text { la parte inferior. }\end{array}$ & $\begin{array}{l}\text { Impacta en primera medida la } \\
\text { fotografía en perspectiva de la } \\
\text { Catedral Basílica de la ciudad de } \\
\text { Popayán y su palacio arzobispal. } \\
\text { Esta estructura arquitectónica } \\
\text { emerge sobre el póster mostrando } \\
\text { el peso de una ciudad colonial } \\
\text { que ha resistido al paso del } \\
\text { tiempo. Al lado derecho se mezcla } \\
\text { y sobresale de una penumbra un } \\
\text { instrumento de música clásica } \\
\text { de cuerda, sobre él reposa el } \\
\text { logotipo de la corporación del } \\
\text { festival. El cielo que aparece sobre } \\
\text { el complejo arquitectónico evoca } \\
\text { la noche. La imagen no contiene } \\
\text { personas, el espacio se encuentra } \\
\text { en completa soledad. La Torre del } \\
\text { Reloj y el cielo se pueden asociar } \\
\text { al cuadro pintado por Efraín } \\
\text { Martínez titulado "Apoteosis a } \\
\text { Popayán". }\end{array}$ & $\begin{array}{l}\text { Al tener el evento una trayectoria } \\
\text { de más de } 50 \text { años, es pertinente } \\
\text { ver el sentido tradicionalista del } \\
\text { mismo. Se puede observar la } \\
\text { Catedral Basílica de la ciudad, } \\
\text { con el complejo del palacio } \\
\text { arzobispal, y en la parte de atrás } \\
\text { de la foto se levanta erguida la } \\
\text { Torre del Reloj, uno de los íconos } \\
\text { arquitectónicos más importantes } \\
\text { de Popayán. El Festival, al igual } \\
\text { que la ciudad, llevan inmerso } \\
\text { el pasar del tiempo, los años } \\
\text { han permitido consolidar una } \\
\text { tradición musical. El instrumento } \\
\text { de la derecha nos remite a un } \\
\text { tipo de música que no es popular } \\
\text { y que tiene un carácter clásico, } \\
\text { en otras palabras se denomina } \\
\text { música culta. El Festival, al ser } \\
\text { oficialmente reconocido como } \\
\text { patrimonio cultural, se sitúa en la } \\
\text { órbita nacional e internacional por } \\
\text { la calidad y trayectoria de músicos } \\
\text { que participan en él. El estilo de } \\
\text { fuente que aparece, recuerda la } \\
\text { caligrafía antigua, aquella que } \\
\text { utilizaban los escribanos en } \\
\text { épocas de antaño. Todo reafirma } \\
\text { una idea de tradición. }\end{array}$ \\
\hline
\end{tabular}


El Festival de Música de Popayán (FESPO), se arraiga en un pequeño grupo que disfruta de la música clásica en sus distintas expresiones, situándolos en una relación de verticalidad y concepción hegemónica de la cultura. Es decir, se apela a una concepción más elitista de la cultura y en consecuencia, sus públicos tienden a ser más focalizados y "exclusivos", pues dada la oferta cultural que maneja esta organización, los públicos a los que se dirige son específicos.

\section{c) Congreso Gastronómico de Popayán}

Su evento central es el Congreso Gastronómico de Popayán. La Corporación hace presencia en Facebook, Twitter y en YouTube. Sus contenidos publicados se concentran en la información referente al Congreso, sus retos, presentaciones y concursos. El Congreso es, quizás, el evento cultural que más ha crecido y mejor se ha consolidado en la ciudad en los últimos lustros. Cada año, hay un país y una región (nacional) como invitados especiales. El Congreso tiene una agenda académica y otra dedicada a la degustación de gran variedad de platos.

Figura 3. Póster Congreso Gastronómico de Popayán.

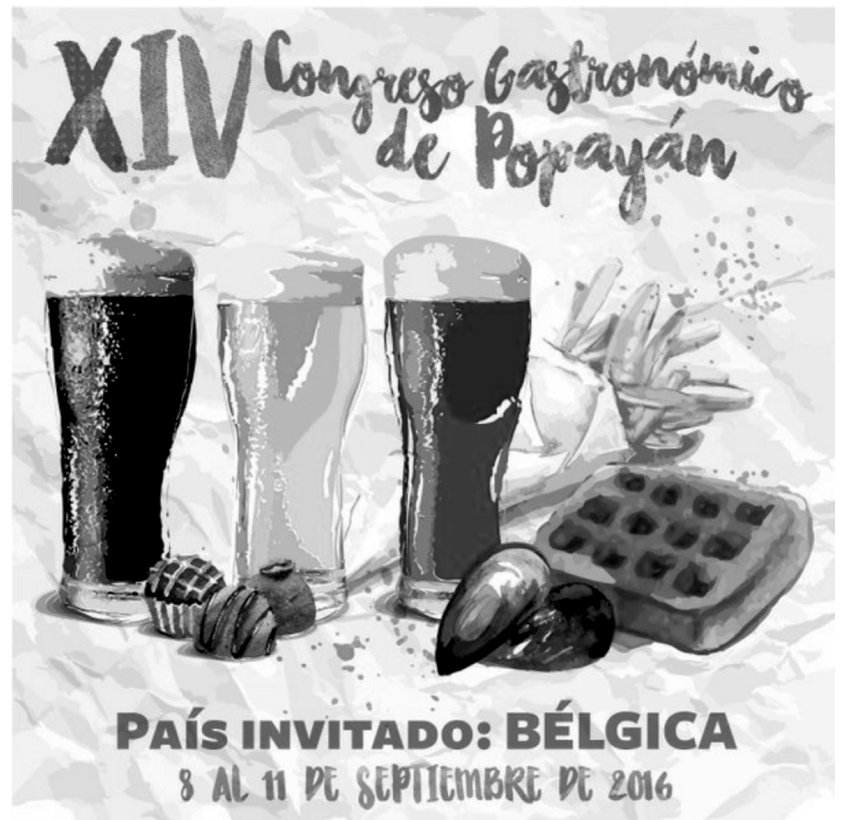

Fuente: Página Web 
Tabla 4. Interpretación y análisis visual del Congreso Gastronómico

\begin{tabular}{|c|c|c|}
\hline Descripción preiconográfica & Análisis iconográfico & Análisis iconológico \\
\hline $\begin{array}{l}\text { El formato del póster encaja } \\
\text { en un cuadrado, es un motivo } \\
\text { diseñado en varios colores, lo que } \\
\text { supone también una impresión } \\
\text { a varias tintas. Los colores que } \\
\text { conforman la composición son } \\
\text { azul oscuro, marrón y amarillo, el } \\
\text { fondo recrea una textura visual, } \\
\text { que da la sensación de arrugas. } \\
\text { Sobre la franja inferior y superior } \\
\text { aparece una caligrafía que informa } \\
\text { acerca del evento. En medio } \\
\text { de estas franjas, aparecen } 3 \\
\text { formas cilíndricas que estabilizan } \\
\text { la composición y el diseño. La } \\
\text { propuesta gráfica nos muestra } \\
\text { una composición en donde las } \\
\text { formas nos remiten a una acción } \\
\text { comestible. }\end{array}$ & $\begin{array}{l}\text { El cuadrante que tiene la imagen } \\
\text { del póster, entra a determinar la } \\
\text { importancia gastronómica del país } \\
\text { invitado, en este caso los vasos } \\
\text { que contienen cerveza informan } \\
\text { acerca de la importancia que tiene } \\
\text { esta bebida Bélgica, así como los } \\
\text { mejillones con las papas fritas, } \\
\text { como una delicia gastronómica } \\
\text { de ese país. La variedad de color } \\
\text { de los vasos nos remonta a una } \\
\text { maestría cervecera de Bélgica, } \\
\text { que puede ir desde cervezas } \\
\text { fuertes a cervezas livianas. } \\
\text { Destaca además en la imagen } \\
\text { chocolates y postres típicos. } \\
\text { Vale la pena mirar la caligrafía } \\
\text { utilizada para el póster, que parte } \\
\text { de una escritura en letra cursiva } \\
\text { que hace una acción envolvente } \\
\text { en la parte superior del formato, } \\
\text { haciendo que llevemos nuestro } \\
\text { punto de atención a las imágenes } \\
\text { de comida que nos presenta esta } \\
\text { versión del congreso. }\end{array}$ & $\begin{array}{l}\text { Lo interesante del póster } \\
\text { está centrado en el carácter } \\
\text { gastronómico como un aspecto } \\
\text { que se impone sobre el } \\
\text { espectador. Este evento rompe } \\
\text { una línea de tradición en la } \\
\text { ciudad, y busca arraigarse en la } \\
\text { sociedad payanesa. El estilo de } \\
\text { la imagen, un tanto provocadora, } \\
\text { juega con los sentidos del } \\
\text { espectador, al punto de hacerlo } \\
\text { sentir olores y sabores. La imagen } \\
\text { apunta a que quien la vea apele } \\
\text { a su imaginación y asocie sus } \\
\text { representaciones con el país } \\
\text { invitado. }\end{array}$ \\
\hline
\end{tabular}

A pesar de ser un evento con un país invitado, también es necesario observar que se tiene una región invitada nacional, en este caso diferentes departamentos de Colombia. Esto quiere decir que la comida local y nacional cobra importancia y tiene un espacio en un evento de características internacionales. Se denota así un aspecto de inclusión que en versiones pasadas casi no se tenía en cuenta. Por consiguiente, cada año el congreso convoca a muchas más personas para el disfrute y aprendizaje gastronómico, lo que demuestra que el evento toma más fuerza y se consolida en la oferta cultura la ciudad.

El Congreso Gastronómico de Popayán es un evento que surge en una clase prestante de la ciudad, para una élite de personas de clases sociales favorecidas, pero con el transcurrir de las versiones tuvo que abrirse camino hacia todas las clases sociales para buscar un sentido de arraigo y pertenencia en la ciudad. Se manejan entonces relaciones de poder verticales y horizontales, procurando un sentido de democratización de su oferta cultural. Se trata aquí de un doble movimiento: elitización de temáticas y contenidos gastronómicos, por una parte, y masificación de prácticas y públicos, por la otra. 


\section{d) Festival de Cine Corto de Popayán}

Nace en el año 2009. El evento anual es organizado por la Corporación Cinematográfica del Cauca. Con presencia en su página web y Facebook, el objetivo es lograr un reconocimiento en la escena cinematográfica nacional. El Festival ha mantenido un buen nivel en la muestra que finalmente se exhibe al público gracias a una importante labor de curaduría audiovisual. Además de la exhibición del material audiovisual, el Festival también programa charlas y talleres con los realizadores asistentes e invitados especiales.

Figura 4. Póster Festival de Cine Corto de Popayán.

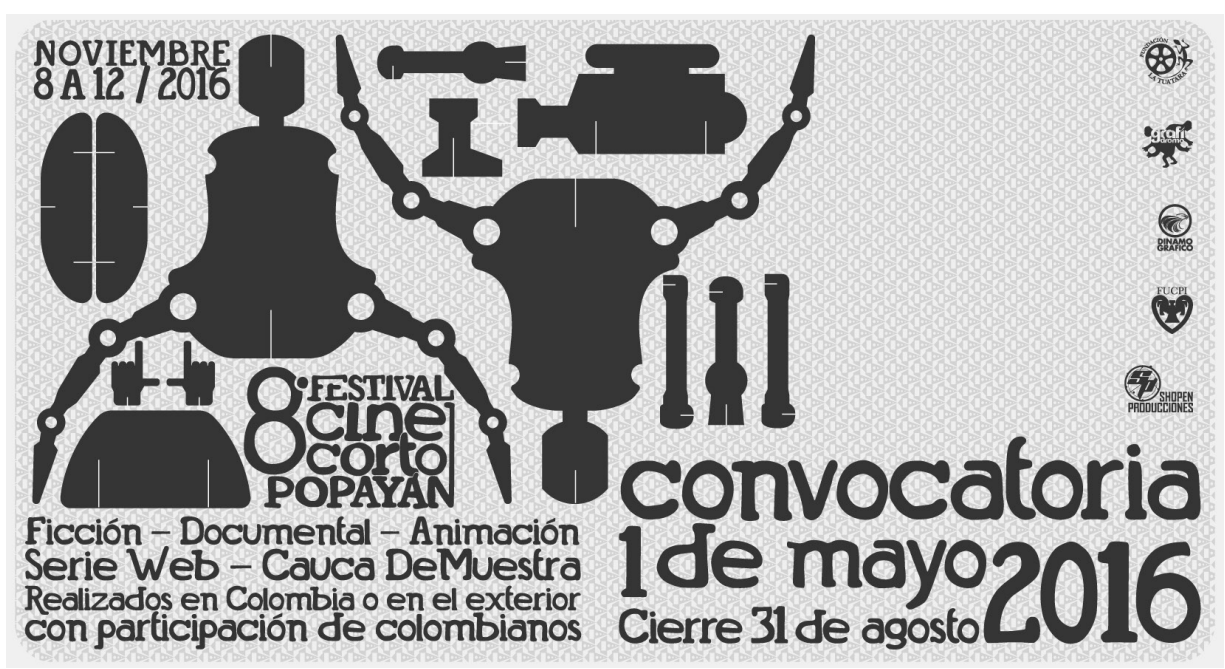

Fuente: Página Web

El evento ha hecho una suerte de "toma" del centro histórico de la ciudad. Para ello, en las exhibiciones públicas de cine, sobrepone sobre las paredes blancas del sector histórico la imagen en movimiento. La concepción imaginaria de una ciudad blanca, inmaculada e incólume, pierde validez cada vez que se proyectan sobre sus paredes las películas que nos ofrece el Festival. El evento es interesante en la medida en que logra afectar los muros de la ciudad, es decir, los interviene con diversos colores, diferentes sonoridades y un sinfín de emociones. Al día siguiente, las paredes icónicas de Popayán, aparecen nuevamente como siembre: en blanco. 
Tabla 5. Interpretación y análisis visual del Festival de Cine Corto

\begin{tabular}{|c|c|c|}
\hline Descripción preiconográfica & Análisis iconográfico & Análisis iconológico \\
\hline $\begin{array}{l}\text { El formato del póster es } \\
\text { rectangular, el sentido espacial } \\
\text { del diseño está ubicado } \\
\text { horizontalmente. Es un motivo } \\
\text { diseñado en dos colores, lo que } \\
\text { supone también una impresión } \\
\text { a varias tintas. Los colores que } \\
\text { conforman la composición son } \\
\text { el azul oscuro, y el gris, el fondo } \\
\text { recrea una textura visual, que } \\
\text { da la sensación de un mosaico } \\
\text { de pequeños baldosines. Sobre } \\
\text { la franja inferior se encuentra la } \\
\text { mayor parte de texto que informa } \\
\text { acerca del evento. Las formas } \\
\text { tienen la característica de terminar } \\
\text { en puntas agudas, presentando, } \\
\text { además, figuras circulares. La } \\
\text { propuesta gráfica nos muestra } \\
\text { una composición en donde las } \\
\text { formas nos remiten a un objeto } \\
\text { en construcción, una especie de } \\
\text { plano que contiene las partes para } \\
\text { un armado. El póster presenta } \\
\text { diversos planos secuenciados con } \\
\text { una lógica de armado. }\end{array}$ & $\begin{array}{l}\text { Las partes con la cuales se } \\
\text { constituye la composición se } \\
\text { asemeja a una especie de } \\
\text { androide, que el Festival siempre } \\
\text { presenta en sus pósteres. La } \\
\text { composición permite dimensionar } \\
\text { una suerte de guión visual que } \\
\text { el espectador tiene que armar. } \\
\text { En esta versión del Festival, } \\
\text { el diseñador juega con la } \\
\text { perspectiva y la construcción de } \\
\text { cada una de las vistas: frontal, } \\
\text { lateral derecha, lateral izquierda, } \\
\text { superior. Con ese juego de vistas, } \\
\text { presenta un modelo para armar, } \\
\text { que el público perfectamente } \\
\text { puede recortar y llevarlo a un } \\
\text { modelo tridimensional. Los } \\
\text { colores planos del diseño, } \\
\text { permiten focalizar la información } \\
\text { respectiva del evento y el tipo } \\
\text { de fuente utilizado convoca a un } \\
\text { tipo de público juvenil, enfocado } \\
\text { a estudiantes universitarios y que } \\
\text { gustan del audiovisual. }\end{array}$ & $\begin{array}{l}\text { El Festival propende por } \\
\text { consolidar un público que disfrute } \\
\text { de la producción audiovisual en } \\
\text { diferentes géneros y formatos. } \\
\text { El evento busca eso de diversas } \\
\text { maneras: mediante la exhibición } \\
\text { de creaciones audiovisuales y a } \\
\text { través de talleres y charlas con } \\
\text { los creadores. Por tanto, cada } \\
\text { año trae a un grupo de invitados } \\
\text { importantes, para que estos, } \\
\text { a su vez, se conecten con el } \\
\text { público del Festival. Así, la ciudad } \\
\text { es convocada a ver cine y a } \\
\text { experimentar nuevas y diversas } \\
\text { sensaciones a partir de lo que } \\
\text { se ve. }\end{array}$ \\
\hline
\end{tabular}

El Festival de Cine Corto de Popayán nace en el seno de un grupo de personas amantes del audiovisual. Uno de sus propósitos es que su público, fundamentalmente universitario - es decir, letrado, en cierto sentido -, lo consolide como un evento de trayectoria en la ciudad. El tipo de relaciones que surgen en el Festival son de horizontalidad y verticalidad, dado que hay un público conocedor del lenguaje cinematográfico y otro que disfruta del audiovisual. Aquí también se da una doble intención: especializarse en la temática audiovisual en cuanto a contenidos, pero al mismo tiempo llegar a una audiencia cada vez más masiva.

\section{Conclusiones}

Este ejercicio de análisis permitió realizar un proceso de lectura del póster, entendiendo este como una pieza comunicativa que hoy en día, gracias a las dinámicas de la comunicación digital, cobra nueva relevancia y llega de forma más rápida a nuevos y más numerosos públicos. Aquí se reafirma la idea según la cual esta herramienta comunicativa puede reforzar, transformar o construir imaginarios culturales. Desde esta óptica es claro que los pósteres se encargan de recrear un aspecto pedagógico, que es precisamente el de educar y formar a un público por medio de nuevas 
alfabetizaciones visuales. No se trata de señalar que el póster en sí mismo es una pieza pedagógica, pero si se tiene en cuenta la carga semántica de este, es claro que como pieza comunicativa que es, el póster contribuye a alcanzar a nuevos públicos y a consolidar los existentes. Así, la formación de públicos si bien no depende exclusivamente de los pósteres, esta se apoya en estas piezas que gracias las tecnologías existentes pueden tener hoy en día mucha más cobertura que décadas atrás.

Como se puede apreciar, la imagen en estudio revela el sentido íntimo de unas relaciones de poder que las mismas organizaciones avalan desde sus propuestas culturales, ya que presentan eventos que buscan un determinado tipo de público. En este sentido, se puede dimensionar un concepto de cultura que cada organización defiende desde su quehacer, debido a las relaciones que los eventos mantienen con el público, en la forma en que unos se abren a la ciudad y otros se cierran a estructuras más íntimas.Las organizaciones estudiadas pugnan por la realización de eventos que procurar nutrir la agenda cultural de la ciudad, cada una quiere establecer una línea de tradición, que en ocasiones solo la pueden otorgar los apellidos y abolengos de una ciudad colonial. Si nos remitimos al póster como pieza comunicativa y educativa, lo podemos observar en la forma en que publicitan sus eventos, puesto que llevan implícito una estética, una idea de ciudad que se quiere transmitir y una narrativa de cómo se concibe la cultura en/de la ciudad.

Por ahora es importante dimensionar el carácter y la fuerza que tienen las imágenes en nuestra cotidianidad, y aún más, las imágenes que surgen a partir de las organizaciones culturales locales. Lo interesante es ver cómo las imágenes que promueven la agenda cultural se abren camino en una ciudad que vive la tensión dual de, por un lado, ufanarse como ciudad cultural, y, por el otro, el decir de muchos de sus habitantes que afirman que "en Popayán no hay nada para hacer". La tensión también se evidencia en la versión que supone que la ciudad no posee una rica y variada agenda cultural y, en contraste, algunos gestores señalan que no hay público para los espectáculos o eventos culturales que se programan y que procuran mantener activa y variada la vida cultural de Popayán.

Lo cierto es que la evidencia muestra que sí hay una oferta cultural pero muchas veces esta no es suficientemente conocida o apropiada. La comunicación digital a la que las organizaciones culturales apelan trata de subsanar la situación y con el póster estas organizaciones buscan una suerte de posicionamiento que contenga también elementos pedagógicos sobre su quehacer cultural. A propósito de estas consideraciones finales, afines al tipo de análisis, proponemos una infografía que resume los puntos principales de análisis. 
Figura 5. Infografía resumen del análisis

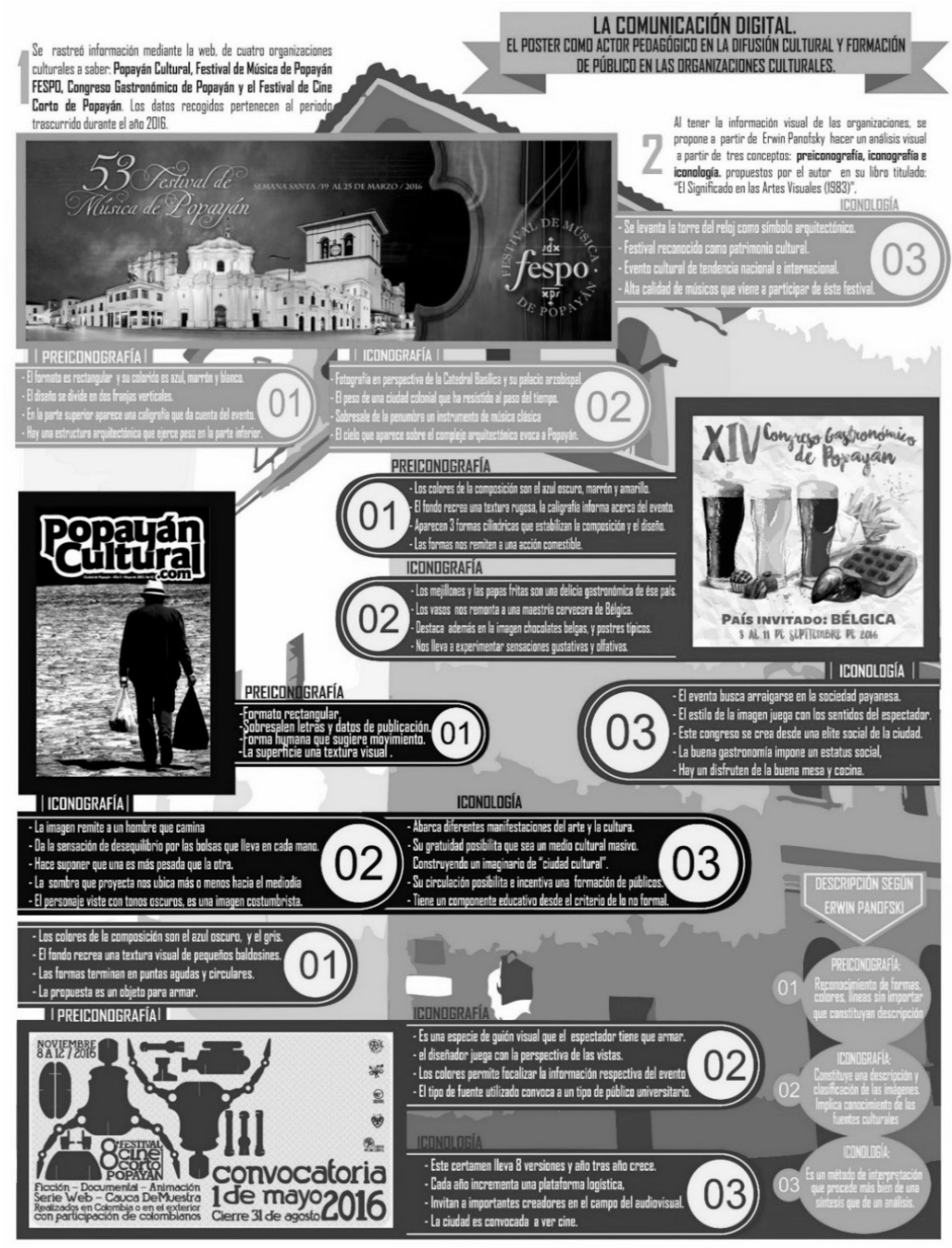

Fuente: Elaboración propia 


\section{Notas}

1 a) Popayán Cultural, b) Corporación Festival de Música Religiosa de Popayán. c) Corporación Gastronómica de Popayán, d) Festival de Cine Corto de Popayán

\section{Referencias}

Arango-Forero, G. (2013). Comunicación digital: una propuesta de análisis desde el pensamiento complejo. Palabra Clave, 16 (3), 673-697. doi:10.5294/3560

Buendía Astudillo, A. (2008). Ciudad, espacio público y comunicación: Una reflexión entorno al discurso pedagógico de y sobre la ciudad. En Córdoba, M. (Coord.). Lo urbano en su complejidad: una lectura desde América Latina. (pp. 257-266). Quito: Flacso.

Buendía Astudillo, A. (2014). Narrativas urbanas y jóvenes escolarizados en Popayán. Comunicación y educación en la formas de narrar y habitar la ciudad. Tesis doctoral. Popayán: Rudecolombia Universidad del Cauca.

Buendía Astudillo, A. (2016). La narrativa urbana de Popayán (Colombia) en la primera mitad del siglo XX. Entre la hidalguía y el patriciado. Chasqui. Revista Latinoamericana de Comunicación, O(132), 351-367. doi: 10.16921/chasqui.v0i132.2675

Buendía Astudillo, A. (2017). Narrar y habitar la ciudad: Jóvenes, comunicación y educación en las narrativas urbanas. Popayán: Editorial Universidad del Cauca.

Crist, R. (2008). La personalidad de Popayán. Cuadernos de antropología y poética, 1(1), pp. 59-73.

García, F. (2013). Identidad urbana y diferencia cultural. El estatuto colonial contemporáneo en Popayán. Tesis doctoral. Doctorado en Antropología. Universidad del Cauca. Popayán.

Gutiérrez del Álamo, F. (2010). Análisis Sociológico del Sistema de Discursos. Madrid: CIS.

Hine, C. (2004) Etnografía virtual. Barcelona. Editorial UOC.

Hilbert, M. \& Peres, W. (2009). La sociedad de la información en América Latina y el Caribe, Desarrollo de las tecnologías para el desarrollo. Santiago de Chile: CEPAL.

Hurtado, D. R. (2011). "Ciudadespacios". Recorridos y tránsitos de las prácticas culturales de jóvenes por la ciudad de Popayán. Revista Latinoamericana de Ciencias Sociales, Niñez y Juventud, 1 (9), pp. 215-226.

Lamy, B. (2006). Sociología urbana o sociología de lo urbano. Estudios demográficos y urbanos. 22 (1): 211-225.

Pereira, J. M. ( 2007) Ciudad, comunicación y construcción de lo público. En: C. M. Yory (Ed.), Espacio público y formación de ciudadanía (pp. 75-94). Bogotá: Pontifica Universidad Javeriana.

Rama, A. (2004). La ciudad letrada. Santiago: Tajamar Editores.

Romero, J. L. (1999). Latinoamérica: las ciudades y las ideas. Medellín: Universidad de Antioquia.

Rosseti, L; (2007). El poder de transformación de la comunicación digital. Razón y Palabra, 12 (59)

Ruano, L., Buendía, A., \& Mamián, M. (2017). La comunicación digital. El póster como actor pedagógico en la difusión cultural y formación de públicos en las organizaciones culturales. Actas del Sexto 
Congreso Iberoamericano en Investigación Cualitativa (Volumen 1 - Investigación Cualitativa en Educación) (pp. 1758-1767).

Scolari, C. (2008): Hipermediaciones. Elementos para una Teoría de la Comunicación Digital Interactiva. Barcelona: Gedisa.

Tocancipá, J. (2006). Cafés en la "Ciudad Blanca": identidad, crisis cafetera y el restablecimiento del orden social en Colombia. Revista de Estudios Sociales (25), pp. 67-79.

Whiteford, A. (1963). Popayán y Querétaro. Comparación de sus clases sociales. Bogotá: Universidad Nacional de Colombia.

Whiteford, A. (2008). What is Popayán? (H. Torres, Ed.) Cuadernos de antropología y poética, 1(1), pp. 13-27.

\section{Luis Eduardo Ruano}

Dr. Sociología. Mág. Métodos de Investigación en CC.SS. Profesor Titular, Universidad Cooperativa de Colombia, UCC, programa de Psicología, Grupo de Investigación PSIEDU. Popayán, Colombia Email: luiseruano@gmail.com

Alexander Buendía Astudillo Dr. Ciencias de la Educación, Mág. Estudios de la Cultura, Comunicador social-periodista. Profesor Titular Depto Comunicación Social, Universidad del Cauca, Grupo de Investigación ECCO. Popayán, Colombia.

Email: abuendia@unicauca.edu.co

Marcelo Mamián

Especialista en Educación Multicultural, Magíster en Educación (modalidad Investigación) Universidad del Cauca. Popayán, Colombia. Email: fabian.marcelus@gmail.com

Correspondencia Alexander Buendía Astudillo Departamento de Comunicación Social Universidad del Cauca Calle $5 \mathrm{~N}^{\circ}$ 4-70 Popayán, Colombia.

Data de submissão: Março de 2017 Data de avaliação: Abril de 2017 Data de publicação: Julho 2018 